\title{
Preparation And Characterization Of The Carbon Fiber Reinforced Epoxy Resin Composites
}

\author{
Prashanth Banakar ${ }^{1 *}$ H.K. Shivananda ${ }^{2}$ \\ ${ }^{I}$ Department Of Mechanical Engineering, Atria Institute Of Technology, Visvesvaraya University, Bangalore- \\ 24, India \\ ${ }^{2}$ Department Of Mechanical Engineering, University Visvesvaraya College Of Engineering, Bangalore \\ University Bangalore-01, India
}

\begin{abstract}
The objective of this research was to gain a better understanding of Mechanical properties of epoxy resin composites reinforced with carbon fiber. The effect of fiber orientation of laminates has been investigated $\&$ experimentation was performed to determine property data for material specifications, the laminates were obtained by hand layup process. The laminates were cut to obtain ASTM standards. This investigation deals with the testing of tensile and flexural strength on a universal testing machine. The graphs that are obtained from the tests are documented. This research indicates that the mechanical properties are mainly dependent on the fiber orientation of laminated polymer composites.
\end{abstract}

Key words: Carbon fiber, Epoxy resin composites, Fiber orientation, laminated polymer composites. Mechanical properties

\section{Introduction:}

Polymers are particularly attractive as matrix materials because they are easily process able and their density is comparatively low when compared to other materials. They exhibit excellent mechanical properties. High-temperature resins are used as composite materials are currently used in the manufacture of high-speed aircrafts, rockets and other related space and electronics. The reinforcements share the major load especially when a composite consists of fibre reinforcements dispersed in a weak matrix (e.g., carbon/epoxy composite), the fibres carry almost all the load. The strength and stiffness of such composites are, therefore, controlled by the strength and stiffness of constituent fiber. Carbon and graphite are superior high-temperature materials with strength and stiffness properties maintainable at temperature up to $2500^{\circ} \mathrm{K}$. carbon fiber composites have been used for various aeronautical, biomedical, defense, industrial and space applications. Originally, these materials were produced for applications where hardware was exposed to extreme temperatures requiring high performance standards, such as solid rocket motors. Today carbon composites are used in commercial as well as military applications. The basic concepts of composites material along with details of earlier works are explained by author at reference [1].The author investigated the influence fiber orientation \& thickness of laminates of different sized glass fibers on the mechanical properties of glass fiber epoxy resin composites .Varatharajan [2] have conducted extensive tensile, flexure and interlaminar tests on glass/polypropylene and glass/polyester composites. Hitchen [3] studied the effect of the fibre length on the fatigue of a short carbon/epoxy composite. They showed that fatigue life is independent of fibre length at any peak strain. Craig D Snyder [5] of Bayer Corporations has showed that addition of long glass fibres has increased the flexural modulus of low density polyurethane structural form. Low density polyurethane composites are a new technology that provides new opportunities for the composites industry. The compressive experimental study to identify the effects of fiber cross sectional aspect ratio on tensile \& flexural properties and failure modes of glass fiber/epoxy composites by using fibers of different cross sectional Shapes was carried out by author[6].Author[7] investigated the influence of fiber orientation and fiber content of an epoxy resin components on mechanical prosperities the main aim of the present investigation was to study the influence of fiber orientation on mechanical properties

\subsection{Material:}

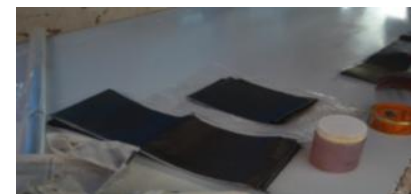

Fig. 1 bi woven carbon fabric, epoxy \& hardener
II. Experimental:

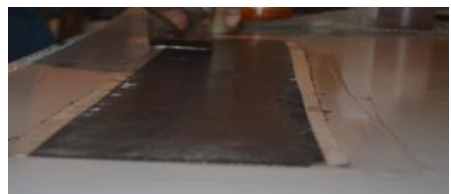

Fig.2 bi woven carbon lamina 
Since bi woven fabrics provide greater damage tolerance and increased popularity in different applications. The present investigation carried on epoxy resin bi woven weft type carbon fibre (240 gsm) and the matrix materials are epoxy resin YD128 and hardener HY140 mixed in appropriate ratio with room temperature curing cycle of 48 hours duration.

\subsection{Instrumental:}

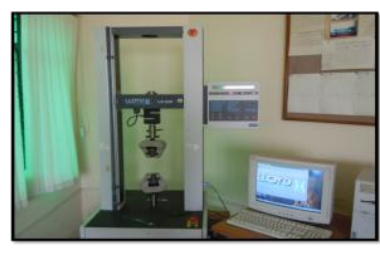

Fig.3 Computer Controlled UTM.

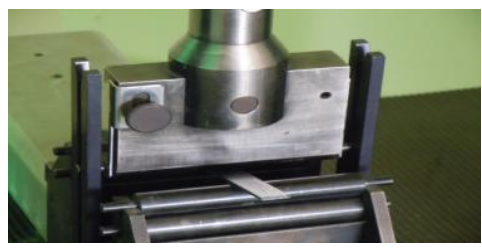

Fig.4 Flexural Fixture

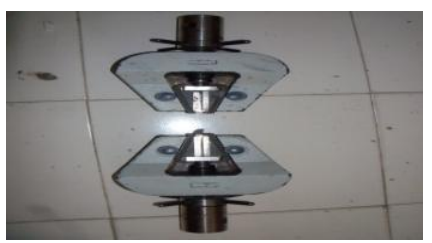

Fig.5 Tensile Fixture

The composite laminates were subjected to various loads and computer controlled UTM. The specimens were clamped and tests were performed. The tests were closely monitored and conducted at room temperature. The load at which the complete fracture of the specimen occurred has been accepted as breakage load.

\subsection{Sample preparation:}

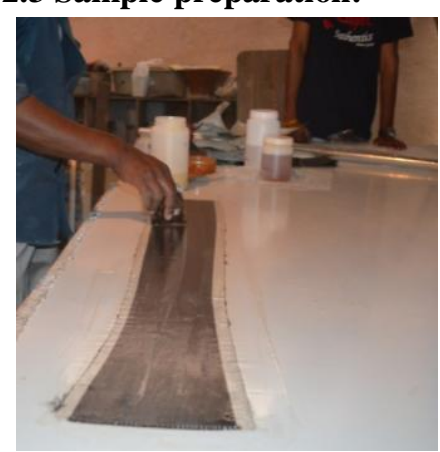

Fig.6.Sample Preparation

\subsection{Test configuration:}

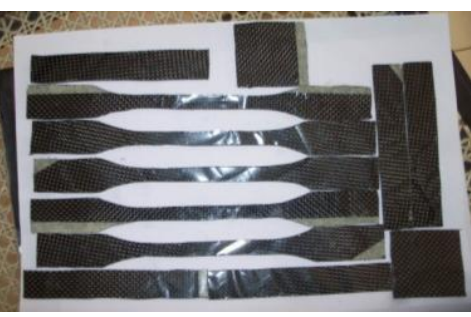

Fig.7Test Specimen

Composites laminated were fabricated at room temperature in shape of rectangle plates by hand layup technique proper care was taken during fabrication of laminates to ensure uniform thickness minimum voids in the material and maintain homogeneity. The laminates were fabricated by placing the Carbon fiber one over the other with a matrix in between the layers. Tools were used to distribute resin uniformly, Compact plies and to remove entrapped air The surfaces of the laminated were covered with 25 micron Mila film to prevent the layup form external disturbances The laminates were cured in room temperature and constant pressure for two days. The laminated test specimens were prepared by a wire cutting machine to suit ASTM dimension and edges were grinded

All composites work processed such that fiber fraction greater than the epoxy resin. For the purpose of investigation three different specimens are prepared according to the angular orientation of the fibres. Three test specimens are prepared for each type of angle oriented specimens.. Specimens selected for the experimentation being $\pm 30^{\circ}, \pm 45^{0}, \pm 90^{\circ}$. The tensile \& flexural properties of the carbon fibre reinforced polymer composites were determined according to ASTM test standard specifications. The average tensile and flexural properties determined from 3 specimen test on each type of orientation

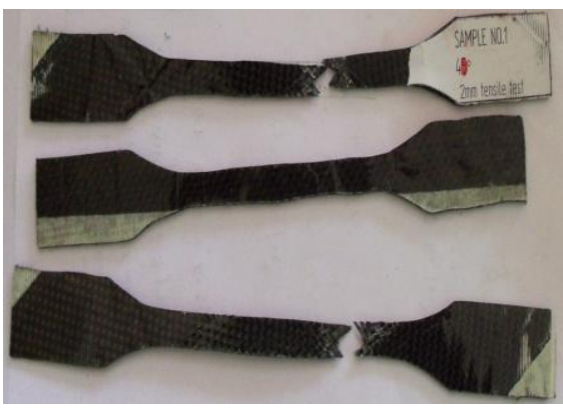

Fig.8 Fractured Tensile Specimens

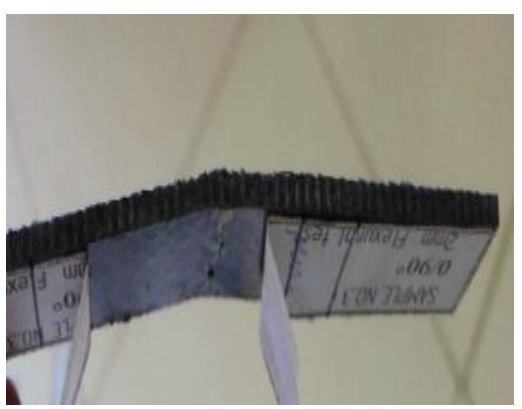

Fig.9 Fractured Flexural Specimen 


\subsubsection{Graphs for Tensile and Flexural Test}

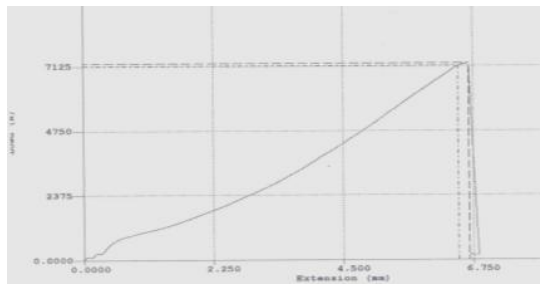

Fig.10 Load Vs Displacement

Tensile Specimen $\left(90^{\circ}\right)$

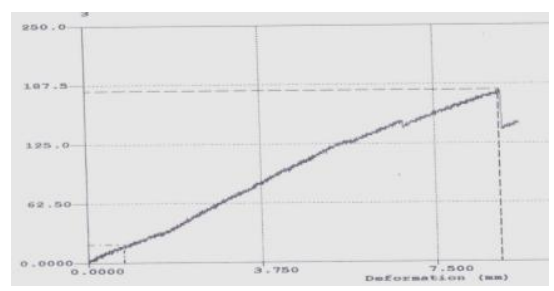

Fig.12 Load Vs Displacement

Tensile Specimen sample $\left(45^{0}\right)$

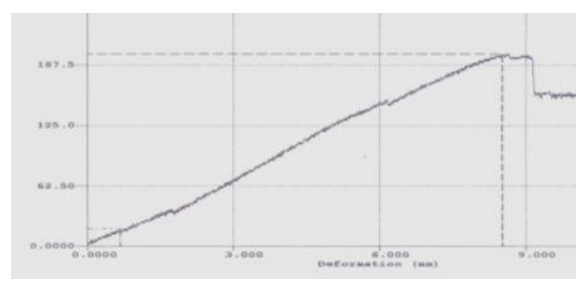

Fig.13 Load Vs Displacement Flexural Specimen sample $\left(45^{0}\right)$

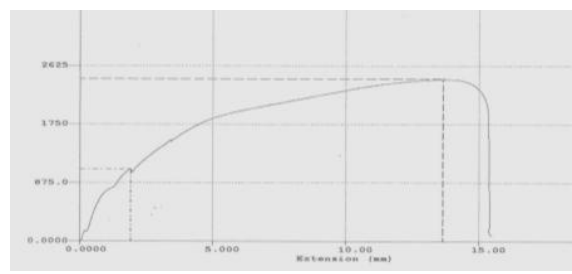

Fig.11 Load Vs Displacement

Tensile Specimen sample $\left(30^{\circ}\right)$

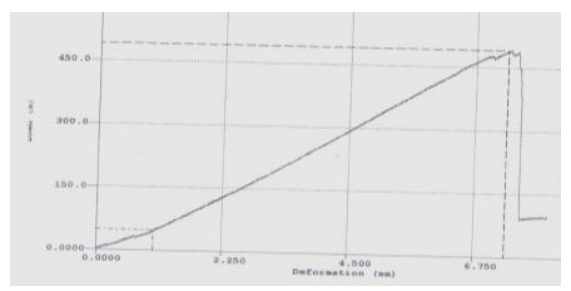

Fig.13 Load Vs Displacement Flexural Specimen Same $\left(90^{\circ}\right)$

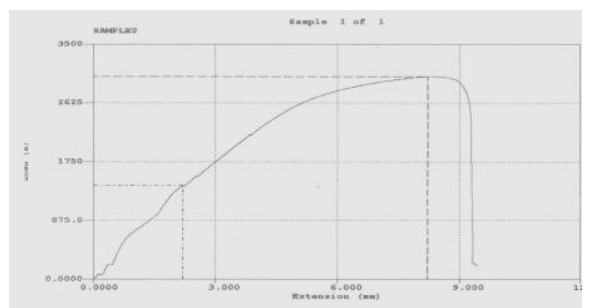

Fig.14 Load Vs Displacement Flexural Specimen Same $\left(30^{\circ}\right)$

\begin{tabular}{|c|l|l|l|l|l|}
\hline $\begin{array}{l}\text { Orientation } \\
(\text { degrees }\end{array}$ & $\begin{array}{l}\text { Max. } \\
\text { breaking } \\
\text { load }(\mathrm{N})\end{array}$ & $\begin{array}{l}\text { Ultimate tensile } \\
\text { strength } \\
\left(\mathrm{N} / \mathrm{mm}^{2}\right)\end{array}$ & $\begin{array}{l}\text { Extension } \\
(\mathrm{mm})\end{array}$ & $\begin{array}{l}\text { Load at high } \\
\text { yield point } \\
(\mathrm{N})\end{array}$ & $\begin{array}{l}\text { Young's } \\
\text { Modulus } \\
\left(\mathrm{N} / \mathrm{mm}^{2}\right)\end{array}$ \\
\hline 90 & 6837 & 341.6 & 5.63 & 3099 & 20364.3 \\
\hline 30 & 2382 & 119.06 & 12.29 & 988.9 & 15922.3 \\
\hline 45 & 3164 & 158.2 & 10.23 & 1028.1 & 4421 \\
\hline
\end{tabular}

Table 1: Tabulated results for Tensile test of CFRP samples

\begin{tabular}{|c|c|c|c|c|c|c|}
\hline $\begin{array}{c}\text { Orientation } \\
(\text { degrees })\end{array}$ & $\begin{array}{c}\text { Max. } \\
\text { Breaking } \\
\text { Load (N) }\end{array}$ & $\begin{array}{c}\text { Ultimate } \\
\begin{array}{c}\text { Flexural } \\
\text { Strength } \\
\left(\mathrm{N} / \mathrm{mm}^{2}\right)\end{array}\end{array}$ & $\begin{array}{c}\text { Deflection } \\
(\mathrm{mm})\end{array}$ & $\begin{array}{c}\text { Load at } \\
\text { high } \\
\text { yield } \\
\text { point (N) }\end{array}$ & $\begin{array}{c}\text { Young's } \\
\text { modulus } \\
\left(\mathrm{N} / \mathrm{mm}^{2}\right)\end{array}$ & $\begin{array}{c}3 \text {-Point } \\
\text { bending } \\
\text { Strength } \\
\left(\mathrm{N} / \mathrm{mm}^{2}\right)\end{array}$ \\
\hline 90 & 463.5 & 11.29 & 7.433 & 45.84 & 5404 & 347.0 \\
\hline 30 & 194.3 & 4.86 & 8.786 & 21.38 & 2226.7 & 145.7 \\
\hline 45 & 204.4 & 5.11 & 13.02 & 18.16 & 2833.6 & 153.3 \\
\hline
\end{tabular}

Table 2: Tabulated results for Flexural test of CFRP samples

The experimental results clearly indicate that When composite materials are designed, the reinforcements are always oriented in the load direction. However if the load direction is variable and not parallel to the fibers it becomes more important to investigate the laminate mechanical behavior. To investigate 
the effect of fiber orientation $\pm 30^{0}, \pm 45^{0}, \pm 90^{0}$ were selected under this study. Specimens with different fiber orientations were prepared under the same conditions as discussed earlier. The experimental results shows that the tensile and flexural strengths are affected by the fiber orientation significantly

\subsubsection{Tensile Properties:}

1. The tensile strength is superior in case of 90 degree orientation.

2. More force is required for fracture of Carbon fibre reinforced polymer composite in case of 90 degree orientation.

3. More elongation will be found in 30 degree orientation. The elongation is less in case of 90 degree orientation.

4. Maximum load at high yield point in case of 90 degree orientation.

\subsubsection{Flexural Properties:}

1. The flexural strength is superior in case of 90 degree fibre orientation.

2. The stiffness property is good at 90 degree orientation.

3. The load at high yield point is maximum at 90 degree orientation.

4. More deflection is found in 45 degree orientation. The deflection is less in case of 90 degree orientation.

\subsection{Conclusions}

The experimental investigations used for the analysis of tensile and flexural behavior of carbon fiber reinforced polymer laminates leads to the following conclusions

In case of 90 degree orientation the external tensile load is equally distributed on all the fibers and transmitted along the axis of the fibers. Whereas in case of other fiber orientations, fiber axes is non-parallel to load axis, resulting in off axis pulling of fibers and increased stress concentration causing the earlier failure of laminates. Even in case of 30 degree and 45 degree orientations the displacement in case of laminates with 45 degree fiber orientation is large compared to laminates with 90 degree and 30 degree orientations, this is due to off axis loading and significant fiber pull out before fracture.

1. The tensile \& flexural strengths are superior in case of 90 degree fibre orientation

2. Specimen sustain greater load at 90 degree orientation specimens than in other orientations.

3. Extension and deflection are minimum in case of 90 degree orientations and maximum in case 30degree orientations.

4. Deflection is maximum at 45 orientation specimens than in other orientations.

[1] Prashanth Banakar, Influence of Fiber Orientation and Thickness on Tensile Properties of Laminated Polymer Composites Int. J. Pure Appl. Sci. Technol., 9(1) (2012), pp. 61-68.

[2] R. Varatharajan et al, Mechanical and machining characteristics of GF/PP and GF/Polyester composites, Material Science and Engineering B 132 (2006), pp 134-137

[3] S.A.Hitchen, S.L.ogin and P.A.Smith, Effect of fibre length on Fatigue of short carbon fibre/epoxy composite, Composites, Vol26, No 4,1995, $p 303$.

[4] Chin-Hsing Chen et al, Pultruded Fibre Reinforced Polyurethane Composites III Static Mechanical, Thermal, and Dynamic Mechanical Properties, Composites Science and Technology 52(1994), pp 427-432.

[5] Craig D.Snyder et al, Low Density Polyurethane composites, Composites 2002 Convention and Trade Show Composites fabricators Association, September 25-27, 2002, Atlanta, Georgia USA.

[6] Deng, S., Ye, L. and Mai, Y.-W. (1999). Influence of Fiber Cross-sectional Aspect Ratio on Mechanical Properties of Glass Fiber/Epoxy Composites, 1. Tensile and Flexure Behavior, Composite Science and Technology, 59: 1331-1339

[7] K. Mohamed Kaleemulla and B. Siddeswarappa(2009). Influence of Fiber Orientation on the In-plane Mechanical Properties of Laminated Hybrid Polymer Composites, Journal of Reinforced Plastics and Composites 2010, Vol. 29, No. 12/2010: 1900-15

[8] Baker, A. A., Callus, P. J., Georgiadis, S., Falzon, P. J., Dutton, S. E. and Leong, K. H. (2002). An Affordable Methodology for Replacing Metallic Aircraft Panels with Advanced Composites, Composites: Part A, 33: 687-696 